\title{
Inpatient waiting: a discussion and policy proposal
}

\author{
JOHN G CULLIS, PHILIP R JONES
}

Waiting lists for inpatient treatment are a widely publicised feature of the National Health Service. They provide ammunition for critics of publically provided medical care, while for advocates of public sector provision they seem, at best, a matter of discomfort and disquiet. An impression has been given that the problem is due to a lack of resources and the solution is an increase in expenditure on NHS hospital facilities. But do waiting lists really represent a problem? Is there an optimal waiting list and can this be different from zero?

We hope, firstly, to outline a set of criteria that might be considered appropriate in discussing waiting lists. If the response to the criteria should be that current waiting lists are too long our second objective is to offer a policy proposal that might enable waiting lists of a desired length to be achieves in an effective manner. Within democratic institutions it is not the prerogative of the individual, or the economist, to determine what policy ought to be undertaken. So we have limited our discussion to establishing a framework in which to ask whether waiting lists are excessive. It is only when this question has been answered satisfactorily that our policy proposal becomes relevant.

\section{Waiting lists: is there a problem?}

Waiting lists will arise in a publically provided service when the price of medical care to the individual patient is not set high enough to equate demand for services with the available supply of beds, operating theatres, etc. Excess demand is registered in the form of a queue for treatment. To remove waiting lists completely would suggest that the NHS was ready to meet immediately all demands made on it. As the NHS's experience is one of increasing demand after increases in supply, this policy seems almost an open ended commitment. It would mean devoting resources to the NHS that could be employed

\footnotetext{
School of Humanities and Social Sciences, University of Bath, Bath BA2 7AY

JOHN G CULLIS, MA, MSC, lecturer in economics and member of the centre for fiscal studies

PHILIP R JONES, MA, PHD, lecturer in economics and member of the centre for fiscal studies

Correspondence to: $\mathrm{Mr} \mathrm{J}$ G Cullis.
}

elsewhere. Blind pursuit of the waiting list problem could prove unacceptably costly. The costs to the community, in terms of the diversion of resources needed elsewhere, should be kept in mind in any discussion of waiting lists, and it is doubtful whether the optimal waiting list for any specialty is zero. Moreover, the optimal waiting list is unlikely to be constant over time and the question should, therefore, be reviewed periodically.

In any review of waiting lists there are two problems-firstly, to interpret the available statistics, and, secondly, to evaluate such an interpretation.

Table I shows that waiting lists have increased in absolute terms between 1949 and 1980, but how should we interpret this information? As a percentage of hospital discharges and deaths waiting lists have fallen, so that to focus on absolute figures may be to distort an image of productivity in the NHS.

It is doubtful whether any precise comparisons can be made easily. Advances in medicine have meant that today's patients expect relief from different complaints from those of their predecessors even 30 years ago. Will waiting time for both sets of patients be strictly comparable? Furthermore, there may be acceptable medical or teaching purposes associated with a waiting list for some surgical specialties.

Though such questions must be asked, recent evidence suggests that waiting time for surgical treatment has increased during the past 10 years. The Department of Health and Social Security has distinguished between urgent and nonurgent cases. The former, the DHSS has deemed, should wait for no more than a month, and the latter for no more than a year. Between 1977 and 1979 the proportion of urgent cases that had to wait more than a month for all surgical specialties rose from two thirds to three quarters. There was also an increase in the percentage of non-urgent cases waiting more than one year. Furthermore, to compare 1971 with 1977, the median waiting time of patients admitted from waiting lists rose for orthopaedic surgery; general surgery; ear, nose, and throat surgery; ophthalmology; urology; plastic surgery; and dental surgery. Identifying an increase in waiting times simply raises more questions. Should this increase be reduced, and if so by how much? Where as a matter of priority should reduction be effected? Certainly, current information suggests that waiting times differ among medical specialties and geographically. For example, in 1979 the waiting list for orthopaedic surgery was 130949 while for urology it was 26550 . For orthopaedic treatment there was an appreciable number of health districts in 1977 in which half or more of patients with non-urgent conditions had already waited for more than a year. By contrast

TABLE I-Waiting list statistics, various years (England)

\begin{tabular}{|c|c|c|c|c|c|c|c|}
\hline Year & $\begin{array}{l}\text { Waiting list: } \\
\text { surgical (including } \\
\text { gynaecology) } \\
\left(\times 10^{3}\right)\end{array}$ & $\begin{array}{l}\text { Waiting list: } \\
\text { all specialties } \\
\left(\times 10^{3}\right)\end{array}$ & $\begin{array}{c}\text { Surgical waiting list } \\
\text { as \% of all } \\
\text { specialty waiting list } \\
(\%)\end{array}$ & $\begin{array}{c}\text { Discharges and } \\
\text { deaths: surgical } \\
\text { (including } \\
\text { gynaecology) } \\
\left(\times 10^{3}\right)\end{array}$ & $\begin{array}{l}\text { Discharges and } \\
\text { deaths: all } \\
\text { speciaities } \\
\left(\times 10^{3}\right)\end{array}$ & $\begin{array}{l}\text { Surgical waiting list } \\
\text { as \% of discharges } \\
\text { and deaths } \\
(\%)\end{array}$ & $\begin{array}{c}\text { All specialties } \\
\text { waiting list as \% of } \\
\text { discharges and } \\
\text { deaths } \\
(\%)\end{array}$ \\
\hline $\begin{array}{l}1949 \\
1959 \\
1969 \\
1979 \\
1980\end{array}$ & $\begin{array}{l}392 \\
406 \\
497 \\
661 \\
614\end{array}$ & $\begin{array}{l}460 \\
447 \\
532 \\
688 \\
640\end{array}$ & $\begin{array}{l}85 \cdot 2 \\
90 \cdot 8 \\
93 \cdot 4 \\
96 \cdot 1 \\
95 \cdot 9\end{array}$ & $\begin{array}{l}1257 \\
1834 \\
2367 \\
2640 \\
2777\end{array}$ & $\begin{array}{l}2788 \\
3783 \\
4968 \\
5400 \\
5670\end{array}$ & $\begin{array}{l}31 \cdot 2 \\
22 \cdot 1 \\
21 \cdot 0 \\
25 \cdot 0 \\
22 \cdot 1\end{array}$ & $\begin{array}{l}16 \cdot 5 \\
11 \cdot 8 \\
10 \cdot 7 \\
12 \cdot 7 \\
11 \cdot 3\end{array}$ \\
\hline
\end{tabular}

Source: Department of Health and Social Security. Health and personal social service statistics for England 1982. London: HMSO, 1982. 
there were districts in which only a few patients had had to wait more than one year. ${ }^{1}$

The questions of how and where waiting lists should be reduced can be answered only after evaluation. Consistency on these issues demands discussion of the value of reducing waiting time. Continual expenditure to achieve this goal may be defended only in terms of the expected associated benefits. In effect, knowing how far to respond to statistical data on waiting time implies that we know the optimal waiting time for medical treatment.

\section{Justifying attempts to reduce lists}

\section{HUMAN CAPITAL}

The human capital approach justifies expenditure if it means a person's earlier return to work. This criterion seems somewhat invidious at times of unemployment and even more so if used selectively for specialties dealing with geriatric patients or those who have long term illness. In effect, while an average figure may be applied for reducing any waiting list, it still fails adequately to consider pain, inconvenience, the quality of life, etc.

\section{WILLINGNESS TO PAY}

If the individual who waits was not locked into the system more people might turn to private medicine. The choice, however, is not to pay for public medical care, for which there is a wait, or to pay for private care. It seems to be between paying (through taxes and national insurance) for public medical care, and, if the individual does not wish to wait, paying extra for private medical care. This expense tends to be prohibitive for many. It is not the case that a small additional payment can be made to secure treatment; instead an "indivisible" expenditure for the full cost of private treatment must be made if the patient is to obtain treatment earlier. The fact that many people do not make this expenditure but remain on the waiting list does not mean to say that everyone on the waiting list would not pay a little extra to speed up their access to medical treatment. Collectively, they may be prepared to finance additional operations, etc. The decision to reduce waiting lists would then be based on a criterion familiar in cost benefit analysis. Even though a market does not directly exist for waiting time, it may be established that individuals would be willing to pay something for a reduction of this inconvenience. If the aggregate willingness to pay exceeds the costs entailed expenditure on reducing the waiting list could seem acceptable.

\section{EQUITY}

In an assessment of willingness to pay for a reduction in waiting time the final figure will be sensitive to the distribution of income in society. If low income groups dominate on waiting lists the recorded figure will inevitably be smaller than if high income groups dominate. In such circumstances it is argued that the proposed project of reducing waiting time may still be acceptable, even though aggregate willingness to pay on the part of potential beneficiaries does not exceed the cost. The case may be defended on "equity" grounds-that is, that it would be "unfair" not to proceed with the project as the benefits are to be enjoyed by the less advantaged sections of the community.

Furthermore, in matters of health the concept of willingness to pay may be rejected on the grounds that individuals are not the best judges of their welfare. If so, it may be necessary to rely instead on the judgments and valuations of "experts."

Both of these arguments may be presented as justifications for expenditure to reduce the waiting list. The need, however, is for explicit formulation so that a clear assessment may be made. Until a framework incorporating any or all of the above criteria is agreed it remains difficult to evaluate waiting time for medical treatment. Indices incorporating such arguments have been presented for managing waiting lists. ${ }^{23}$ Certainly, if extra money is to be spent to reduce current waiting times it should be clear against which criteria this is justified.

\section{Waiting lists: is there a solution?}

It would be foolish not to accept that some commentators and administrators perceive existing waiting lists as a problem. Hence we outline a policy proposal intended to reduce them to whatever target is deemed acceptable. Our suggestion is essentially to apply selective subsidies in different specialties for private medical treatment. To the extent that the private sector expands to treat those subsidised patients the waiting list will be reduced. In certain cases it may be shown that such a policy would cost the Exchequer less than an alternative policy of direct expansion of the NHS. The following example outlines the mechanics by which such a subsidy policy might operate.

\section{POLICY SUGGESTION}

Waiting lists are a characteristic of non-market allocation systems-that is, the NHS allows you to register as a potential consumer in an observable fashion. This is not the case in market circumstances, where absolute prices determine that the highest bidders obtain the present output or provision, and relative price movements stimulate changes in the level of output. So it may be necessary to resort to the market mechanism to reduce the numbers waiting in the NHS.

We have tried to substantiate this in the hypothetical example in table II. The figures are purely illustrative and are based on the initial assumptions that in a given health area there are 1667 private patients treated, 2333 NHS patients treated, and 1000 waiting patients for a given cold surgical condition. It is further assumed that both the private and NHS costs of treating such cases are $£ 2000$ and that a limit of $£ 400000$ per period is available for policy initiatives. It is also maintained that doctors acting as the agents of patients are able to increase the demand for their own services (not necessarily in a cynical way or for unworthy reasons). With this as background, two policy options directed at reducing the size of the waiting list are compared.

The first, labelled option $\mathrm{A}$, outlines the likely consequences of expanding capacity in the NHS. With a fixed budget of $£ 400000$ and a cost per case of $£ 2000$ clearly the best outcome that can be expected is that given in the row labelled period 2 . The increased NHS expenditure has cut the waiting list by 200 , from 1000 to 800 , increased the number of NHS patients treated by 200 , and raised the total Exchequer expenditure from $£ 4666000$ to $£ 5066000$. The Achilles' heel of expanding NHS capacity in this way is the doctors' response. It has been suggested elsewhere ${ }^{4}$ that doctors reassess their notions of who ought to be treated or wait for treatment in line with available capacity in the NHS, the result being that demand for treatment increases as supply is expanded. Thus period 3 will not be a replication of period 2 . The argument is that new cases would be found and more treatments would be deemed appropriate as different decision thresholds are applied to a given population of potential inpatients. In table II it is assumed that demand is increased in this way by 200 cases so that the waiting list norm is re-established and the target reduction is not achieved.

Option B envisages using a selective subsidy directed at individuals suffering from the sort of conditions that predominate on waiting lists-for example, varicose veins, hernias, etc. A selective subsidy would take some waiting patients into the private sector, thus relieving the pressure on the NHS. In table II the effect on our example of introducing a $£ 120$ subsidy is given in the row labelled period 2 under option $\mathrm{B}$. It produces a similar result to period 2 under option $\mathrm{A}$ in that the waiting 
list is reduced by 200 . The differences that arise, however, relate to the facts that the private sector is expanded (1667 to 1867 patients treated) and the Exchequer cost is $£ 224000$. This sum is relatively small because the remainder of the extra costs is being borne by the individuals and does not show up in the government's budget. This is clearly a rather dubious advantage for option $B$.

A greater advantage for this second approach is shown when we postulate the same increase in demand as occurred with option A. With option B such an increase in demand serves to expand the private sector by 200 to 2067 cases and raises the Exchequer cost by $£ 248000$ compared with the period 1 budget. The waiting list remains at 800 and the number of patients treated by the NHS remains constant at 2333 .

Increases in demand generated by doctors are all the more likely in option B because it provides a financial incentive for this to occur. Conceivably any subsequent increases in demand create the outcomes in the rows labelled period $\mathrm{N}$ and period $\mathrm{N}+1$. The numbers here are based on the same $£ 120$ subsidy larger the subsidy and the greater the range of conditions it is applied to the larger will be the fall in the waiting list that might be achieved and the less likely it is that NHS doctors can find new types of waiting conditions and thus upset the above scenario. Those patients who have to wait are likely to be those with illnesses that have few alternative avenues of treatment, and thus the more favourable waiting times associated with a shorter list are unlikely to draw in large numbers of patients previously assigned to alternative regimens of treatment.

\section{Implementation issues and possible criticisms}

In economics it is a commonplace observation that the weld between theory and empirical work stands proud; this applies equally to the weld between policy proposals and implementation. How does a hypothetical example apply to the real world ? The obvious deficiency for practical purposes is the lack of knowledge of the actual demand and cost conditions in the

TABLE II-Hypothetical waiting list policy outcomes

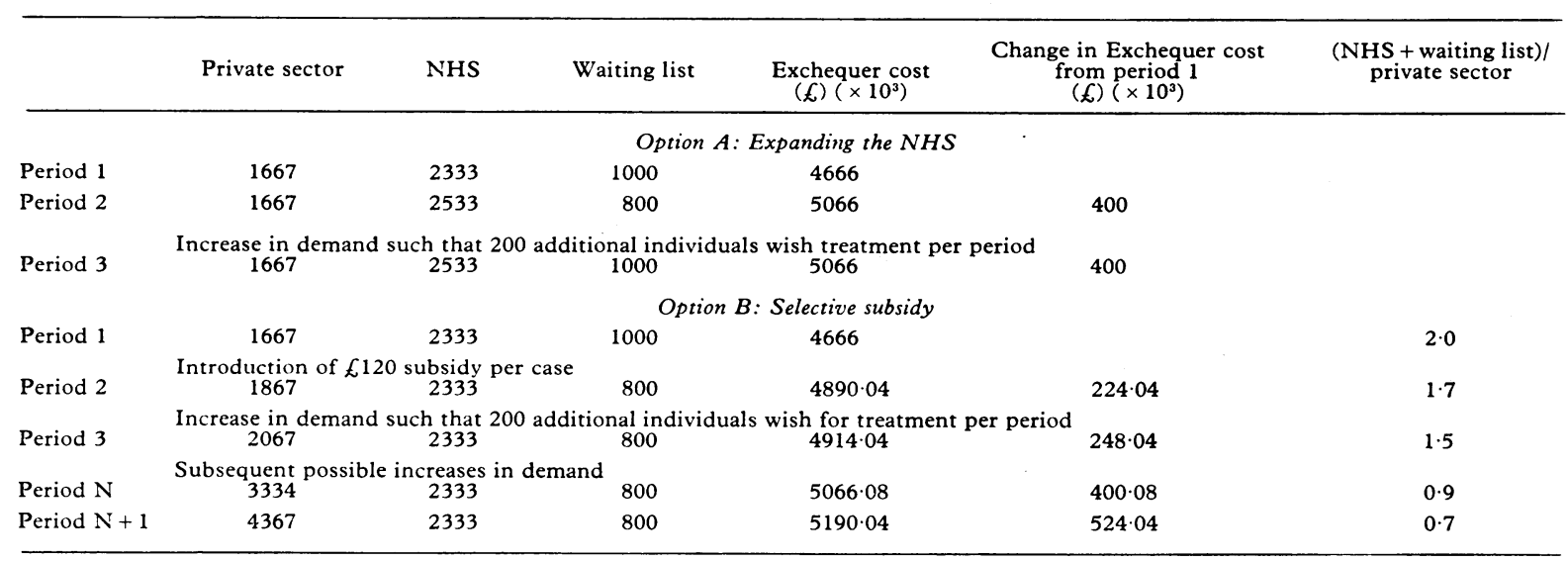

but are related to increased demand. Period $\mathrm{N}$ illustrates roughly the Exchequer cost's break even point of the policy. With 3334 private patients treated, all eligible for subsidies, the Exchequer costs just top the $£ 400000$ available for policy action. The 200 target reduction in the waiting list is, however, still maintained. Period $\mathrm{N}+1$ illustrates the position where continual increases in demand have generated unacceptably large Exchequer expenditure.

Fortunately there is a simple rule of thumb that may be adopted to show when option $B$ is in danger of exceeding the budget allocated by the Exchequer. This is illustrated by the ratio in the fourth column of the lower (option B) part of table II. When the ratio of the number of NHS patients plus the waiting list to the private sector patients is greater than unity there is no danger of the budget overrunning. ${ }^{5}$ Once this ratio falls below unity the allocated budget will be exceeded. If the ratio equals unity then option $A$ and option $B$ have identical expenditure implications for the Exchequer. So the policy needs to be sensitive to this ratio if the budget limit is not to be exceeded.

If the analysis underlying this example is accepted several important advantages are secured by adopting option B rather than A. Firstly, expansion of the NHS will not be a successful method of reducing the waiting list. Historically this has been the case (table I). Secondly, not only can selective subsidies be effective in reducing the waiting list but they will do so even in the presence of supplier induced demand. Thirdly, subsidies will be expenditure effective to the Exchequer in a wide range of circumstances. Fourthly, there is a simple rule of thumb that may be used to indicate when the subsidy policy is outstripping the budget allocated to the waiting list policy. Finally, the
NHS that will dictate the attractiveness (or otherwise) of the proposal. Given this ignorance, a pilot scheme would be a sensible starting point, perhaps preceded by a survey to get some idea of the size of subsidy required to induce some waiting list patients to seek private treatment. Furthermore, the range of illnesses for which the subsidy is available must be decided. This will largely be determined by the amount of money allocated to the scheme.

A second point to be emphasised is that a moderate expansion of overall medical care will be needed to ensure treatment of the specified types of cases in the schemes because if a subsidy simply takes resources from the NHS it will leave the overall number of cases treated unchanged. There are no free lunches.

This policy suggestion raises the question of equity. Will it not be the relatively well off who will find the subsidy attractive? Perhaps, but it could be argued that this is an income distribution problem that should be treated as such with the use of the tax transfer policies available to governments. In any case there is little evidence that postwar governments have used tax transfer policies to affect income distribution appreciably. Income related subsidies would complicate the scheme but might be an appropriate answer to the problem of equity.

Opponents of private medical care might argue that this proposal reads like a cosmetic mechanism that allows the NHS to hide the waiting list to some extent by hiving patients off to private treatment. Indeed, this is what it is. We have assumed, however, that the waiting list is a problem that deserves resolution. We should emphasise that this proposal envisages only a limited expansion of the private medical sector. If successful it 


\section{$£ 9 \mathrm{~m}$ to help primary care in inner cities}

During the debate on the National Health Service in the House of Commons on 27 October the Secretary of State for Social Services, Mr Norman Fowler, announced that the Department of Health and Social Security would be providing $f 9 \mathrm{~m}$ over the next four years to improve primary health care in inner cities. The grants will fund several inner city care projects in response to the Acheson and Harding reports. ${ }^{12}$

In addition to providing extra funds for training health visitors and district nurses there will also be new measures to improve general practitioner premises, new incentives to group practice, and $£ 1$ million for primary health care projects this year.

\section{Better improvement grants}

The problem of unsatisfactory practice premises will be tackled in several ways. A higher level of improvement grant is being introduced to enable doctors in selected areas in England to upgrade poor quality surgery premises or improve practice organisation. The scheme is temporary and will run for three years. Projects already in the pipeline will not be eligible. The total amount that will be made available is $£ 2 \frac{1}{2}$ million, which will be allocated by the family practitioner committees concerned. These family practitioner committees match or include the areas of local authorities that have the status of partnership or programme authorities under the government's inner cities policy or fall within the area of the London dockland development corporation. Higher grants will be restricted to these local authority areas. At the discretion of the family practitioner committee and subject to certain conditions being fulfilled improvement grants of $60 \%$ of the approved cost may be given by the committee, compared with $33 \%$ under the existing countrywide scheme.

A circular giving further details of the new improvement grant scheme will be issued shortly. It will explain that the $60 \%$ grant will be subject to a maximum of $£ 10000$ per doctor with an overall limit of $£ 25000$ in respect of any one project; there will be no right for the doctor to make representation to the Secretary of State if he is dissatisfied with the committee's decision; the scheme is additional to and separate from the existing improvement grants scheme. A general practitioner will not be able to receive both a $60 \%$ grant and a $33 \frac{1}{3} \%$ grant in respect of the same project.

\section{Role of family practitioner committees}

All family practitioner committees, not just those in inner cities, are being asked to adopt a more active role in advising doctors on premises, monitoring standards through regular visiting of surgeries, and promoting improvements. Minimum standards of accom modation will be set and family practitione committees will be empowered to withhold after due consideration and notice, some or all of the reimbursement of rent and rates that they make to doctors, where the minimum standards are not achieved. Discussions on the detail with the professions are now well advanced. New guidance is also being prepared on the design of primary health care premises, including doctors' own surgeries, with particular emphasis on adapting and improving existing buildings.

Inner London has a high proportion of single handed doctors-32\% compared with $13 \%$ nationally. Some other inner cities are also well above the national average. The government has decided to offer new financial incentives to group practice in inner cities for a limited period, and detailed proposals are now being worked out with the medical profession.

\section{Help for nursing services}

The Acheson report pointed out that health authorities in inner London were forced to spend more on training health visitors and district nurses because of their recruitment difficulties. This is also the case in several other inner city areas. The government has already allocated a total of $£ 1$ million over
1982-3 and 1983-4 to those inner city authorities in London and elsewhere with the greatest problems to help in the training of health visitors and district nurses, and this help will continue for another two years.

In addition $£ 1$ million is being made available this year to those regional health authorities containing inner city partnerships and urban programme authorities for use on projects to improve primary health care in those areas. The regional health authorities are being asked to prepare such projects in consultation with district health authorities. They might include, for example, the development of night nursing services, improvements in the supply of aids and equipment available to nurses, or minor capital schemes to improve working conditions or patient facilities.

Together these measures to support health authorities will cost almost $£ 2$ million this year. Next year a total of $£ 3$ million will be available and further details on how that is to be used will be announced later.

Mr Norman Fowler said: "These steps are only part of our efforts to tackle the problems of primary health care in inner cities. We will continue to concentrate help on the most needy areas as we seek to strengthen primary health care services generally in partnership with health and local authorities and the professions."

${ }^{1}$ London Health Planning Consortium Group on Primary Health Care in Inner London. Report. London: DHSS, 1981. (Acheson report.)

${ }^{2}$ Standing Medical Advisory Committee and Standing Nursing and Midwifery Advisory Committee. The primary health care team. London: DHSS, 1981. (Harding report.)

\section{Sales of solvents}

Representatives of retailers' and manufacturers' organisations were invited to meet the parliamentary secretary for health, $\mathrm{Mr}$ John Patten, to discuss action that could be taken to coordinate voluntary restraint on sales of solvent based products. The meeting on 8 November explored the possibility of drawing up a flexible set of guidelines for people selling solvents, aerosols, and other products liable to misuse by inhalation.

Talking Point-continued from page 1485

would take away a stick from the hands of those who like to belabour the NHS. Furthermore, even the most ardent supporters of the NHS recognise a role for a small private sector, ${ }^{6}$ not only as a safety valve or exit for those dissatisfied in the NHS but also as an element of competition that may help to keep the NHS efficient.

\section{References}

${ }^{1}$ Department of Health and Social Security. Orthopaedic services: waiting time for out-patient appointments and in-patient treatment. London: HMSO, 1981.
2 Culyer AJ, Cullis JG. Some economics of hospital waiting lists. fournal of Social Policy 1976;5 (part 3):239-64.

${ }^{3}$ Frost CEB. How permanent are NHS waiting lists? Social Science and Medicine 1980;14c:1-11.

${ }^{4}$ Cooper MH. Rationing health care. London: Croom Helm, 1975.

${ }^{5}$ Cullis JG, Jones PR. NHS waiting lists: an assessment of competing explanations and a policy proposal. University of Bath papers in political economy, No 17. Bath: University of Bath, 1983.

${ }^{6}$ Culyer AJ. Health services in the mixed economy. In: Lord Roll of Ipsden, ed. Proceedings of section $F$ (economics) of the British Association for the Advancement of Science. London: British Association for the Advancement of Science, 1980:128-44. 